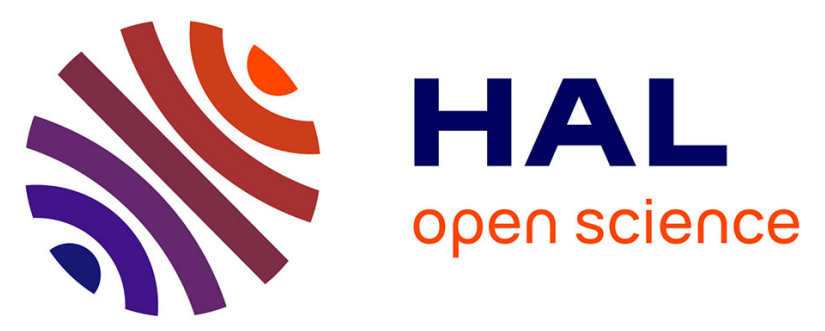

\title{
Hydration of Biodentine, Theracal LC, and a Prototype Tricalcium Silicate-based Dentin Replacement Material after Pulp Capping in Entire Tooth Cultures
}

Josette Camilleri, Patrick Laurent, Imad About

\section{- To cite this version:}

Josette Camilleri, Patrick Laurent, Imad About. Hydration of Biodentine, Theracal LC, and a Prototype Tricalcium Silicate-based Dentin Replacement Material after Pulp Capping in Entire Tooth Cultures. Journal of Endodontics, 2014, 40 (11), pp.1846-1854. 10.1016/j.joen.2014.06.018 . hal03547636

\author{
HAL Id: hal-03547636 \\ https://hal.science/hal-03547636
}

Submitted on 28 Jan 2022

HAL is a multi-disciplinary open access archive for the deposit and dissemination of scientific research documents, whether they are published or not. The documents may come from teaching and research institutions in France or abroad, or from public or private research centers.
L'archive ouverte pluridisciplinaire HAL, est destinée au dépôt et à la diffusion de documents scientifiques de niveau recherche, publiés ou non, émanant des établissements d'enseignement et de recherche français ou étrangers, des laboratoires publics ou privés. 


\title{
Hydration of Biodentine, Theracal LC, and a Prototype Tricalcium Silicate-based Dentin Replacement Material after Pulp Capping in Entire Tooth Cultures
}

\author{
Josette Camilleri, BChD, MPbil, PhD, FADM, FIMMM, ${ }^{*}$ Patrick Laurent, PhD, DDS, ${ }^{\dagger}$ \\ and Imad About, $\mathrm{PbD}^{+}$
}

\section{Ahstract}

Introduction: The calcium-releasing ability of pulpcapping materials induces pulp tissue regeneration. Tricalcium silicate-based materials produce calcium hydroxide as a by-product of hydration. Assessment of hydration and calcium ion leaching is usually performed on samples that have been aged in physiological solution for a predetermined period of time. The hydration and activity of the materials in vivo may not be similar to those displayed in vitro because of insufficient fluid available in contact with dentin. The aim of this research was the assessment of hydration of Biodentine, Theracal LC, and a prototype radiopacified tricalcium silicate-based material after pulp capping and to compare it with direct hydration in an aqueous solution. Methods: The extent of hydration of Biodentine, Theracal LC, and a prototype radiopacified tricalcium silicate-based material with a similar composition to Biodentine but not incorporating the additives was assessed by scanning electron microscopy and energy dispersive spectroscopy of polished specimens after being allowed to hydrate in Hank's balanced salt solution for 14 days. The extent of hydration was compared with material hydration when used as direct pulp capping materials by using a tooth culture model. Material activity was also assessed by $\mathrm{x}$-ray diffraction analysis to investigate the deposition of calcium hydroxide by the materials, and calcium ion leaching in Hank's balanced salt solution was assessed by ion chromatography. Results: Biodentine and the prototype tricalcium silicate cement hydrated and reaction by-products were deposited in the cement matrix both after pulp capping and when incubated in an aqueous solution. Calcium hydroxide was formed, and calcium ions were leached in solution. Theracal LC hydration was incomplete because of the limited moisture diffusion within the material. Thus, no calcium hydroxide was produced, and a lower calcium ion leaching was recorded. Conclusions: Theracal LC had a heterogeneous structure with large unhydrated particles because not enough moisture was present to allow hydration to proceed. Biodentine composition was shown to be optimized, and the environmental conditions did not affect material microstructure. Biodentine exhibited formation of calcium hydroxide and calcium ion leaching, which are beneficial to the dental pulp. (J Endod 2014; $\mathbb{\square} 1-9$ )

\section{Key Words}

Biodentine, hydration, Theracal LC, tooth culture pulp capping, tricalcium silicate

Dulp-capping materials are necessary to protect the pulp from thermal, chemical, and other noxious stimuli. Calcium hydroxide has been the material of choice for pulp capping for several years. More recently with the introduction of mineral trioxide aggregate (MTA) for clinical use, tricalcium silicate-based materials have become indicated for use as pulp-capping materials (1). MTA produces calcium hydroxide as a byproduct of hydration (2). Both materials solubilize bioactive molecules such as transforming growth factor $\beta 1$ from the dentin $(3,4)$. This factor is involved in pulp progenitor cell migration to its production site and in the subsequent odontoblastic differentiation and dentin bridge formation under tricalcium silicate-based materials (5). Thus, the mode of action of MTA can be assumed to be similar to that of calcium hydroxide. When used as a pulp-capping agent, MTA exhibited comparable $(6,7)$ or better $(8,9)$ clinical and radiographic success rates to calcium hydroxide. The main disadvantages of MTA are the long setting time and the material incompatibility with other dental materials when layered $(10,11)$.

Second-generation calcium silicate-based materials indicated for use as pulpcapping materials are modified and exhibit a reduced setting time, thus making them more suitable in clinical use. Biodentine is composed of tricalcium silicate cement, zirconium oxide, and calcium carbonate, which, when mixed with water, calcium chloride, and a water-soluble polymer, sets in 12 minutes (12) and forms calcium hydroxide as a by-product of hydration (13). Biodentine is bioactive because it increases murine pulp cell proliferation and biomineralization (14). Furthermore, it induces transforming growth factor $\beta 1$ release from human pulp cells and early dental pulp mineralization (5). In contact with animal pulps, Biodentine induced cell proliferation and formation of mineralization foci, which were strongly positive for osteopontin. At longer time points, the formation of a homogeneous dentin bridge at the injury site, secreted by cells displaying an odontoblastic phenotype, was observed. These observations were similar to those for MTA, but calcium hydroxide showed porous organization, suggesting a reparative process different from those induced by calcium silicate cements $(15,16)$. In a recent clinical study, Biodentine exhibited complete 
dentinal bridge formation and an absence of inflammatory pulp response. Layers of well-arranged odontoblast and odontoblast-like cells were found to form tubular dentin under the osteodentin (17).

Another calcium silicate-based material indicated for use as a pulp-capping material is Theracal LC. It is light-curable and indicated for use as liner under composite restorations aiming to achieve a bond between the different layers of materials, thus reducing microleakage. Theracal LC is a resin-modified Portland cement-based material that has demonstrated release of more calcium than ProRoot MTA and Dycal and thus was able to alkalinize the surrounding fluid (18). This is in contrast to a recent study evaluating the hydration of Theracal LC compared with Biodentine where Theracal LC exhibited low calcium ion release and a slower reaction rate than Biodentine. In addition, no calcium hydroxide was formed as a by-product of hydration (19). Contact of Theracal LC with pulp cells resulted in a reduction in cell metabolism, a reduced protein expression, and cell toxicity (20).

Assessment of hydration and material activity of calcium silicate-based cements is usually performed in vitro in standardized conditions, thus enabling researchers to compare the data obtained. It is difficult to relate in vitro conditions to in vivo situations because the replication of environmental conditions is not possible. Biodentine has demonstrated bioactivity, enhanced material hydration, and calcium ion release in vitro $(13,19,21)$. The in vitro properties reflect well with the findings of material activity at the cellular (5, 14), histologic (15, 16), and clinical (17) levels. Although Theracal LC is certified as suitable for clinical use as a pulp-capping material, as yet the interaction of the material with the pulp is not so well-reported. Although Theracal LC releases calcium ions in solution (18), the pulpal response was not promising (20). Theracal LC is resin-modified, and the resin monomers may cause the adverse pulp reactions. Furthermore, Theracal LC does not include water for material hydration. It depends on the water taken up from the environment and its diffusion within the material.

The aim of this research was to assess the hydration of Biodentine and Theracal LC and a prototype radiopacified tricalcium silicate-based material after their application as pulp-capping materials for 14 days and to compare it with direct hydration for 14 days in an aqueous solution.

\section{Materials and Methods}

The materials used in this study included a prototype material composed of tricalcium silicate cement (Mineral Research Processing, Meyzieu, France) with $20 \%$ zirconium oxide $\left(\mathrm{ZrO}_{2}\right.$; Sigma-Aldrich, Buchs, Germany) that was mixed with water at a water-to-powder ratio of 0.35 (TCS-Zr-20) developed at the University of Malta, Biodentine (Lot no. B05128; Septodont, Saint Maur-des-Fosses, France) that was mixed according to manufacturer's instructions namely by adding the liquid provided in the vial to the powder in the capsule and triturating in an amalgam mixer for 30 seconds, and TheraCal LC (Lot no. 1200006458; Bisco Inc, Schaumburg, IL), which was dispensed from a syringe and light-cured with an LED light-curing unit (Woodpecker Zhengzhou Smile Dental Equipment Co, Ltd, Zhengzhou, Henan, China) for 20 seconds per increment.

\section{Characterization of Set Materials Assessment of Hydration of Materials Stored in Aqueous} Solution. Six cylindrical specimens measuring $10 \mathrm{~mm}$ in diameter and $2 \mathrm{~mm}$ high were prepared from each material type. The materials were allowed to harden: 1 hour for the prototype material, 12 minutes for Biodentine, and immediately for Theracal because it hardened on application of light from light-curing device. Once set, the materials were immersed in $5 \mathrm{~mL}$ Hank's balanced salt solution (HBSS) (H6648; Sigma-Aldrich, St Louis, MO) for 14 days at $37^{\circ} \mathrm{C}$. The composition of the HBSS was $(\mathrm{g} / \mathrm{L}) 0.4 \mathrm{KCl}, 0.06 \mathrm{KH}_{2} \mathrm{PO}_{4}$ anhydrous, 0.35 $\mathrm{NaHCO}_{3}, 8.0 \mathrm{NaCl}, 0.05 \mathrm{Na}_{2} \mathrm{HPO}_{4}$ anhydrous, and 1.0 d-glucose. The specimens were then retrieved from the soaking solution, vacuum desiccated, and embedded in resin (Epoxyfix; Struers GmbH, Ballerup, Denmark), and polished specimens were attached to aluminum stubs, carbon coated, and viewed under the scanning electron microscope (Zeiss MERLIN Field Emission SEM; Carl Zeiss NTS GmbH, Oberkochen, Germany). Scanning electron micrographs of the different material microstructural components at different magnifications in backscatter electron mode were captured, and energy dispersive spectroscopy was carried out. The degree of hydration was assessed by observation of deposition of reaction by-products around the unhydrated cement particles and in the cement matrix.

\section{Direct Pulp Capping by Using an Entire Culture Tooth Model and Assessment of Hydration after Direct Pulp Capping}

Human third molars extracted for orthodontic reason and collected in agreement with French legislation (informed patients' and parents' consent and Institutional Review Board approval of the protocol used) were used. Immediately after extraction, each tooth was stored at $4^{\circ} \mathrm{C}$ in minimum essential medium supplemented with $300 \mathrm{IU} / \mathrm{mL}$ penicillin, $300 \mu \mathrm{g} / \mathrm{mL}$ streptomycin, and $0.75 \mu \mathrm{g}$ amphotericin B (Lonza, Vervier, Belgium). Eighteen teeth with immature roots and wide open apices were selected, cleaned, dipped for 10 seconds in a $0.2 \%$ aqueous chlorhexidine solution, and rinsed for 30 seconds in phosphate-buffered saline.

A large and deep occlusal cavity with pulp exposure was prepared in each tooth with a round diamond bur mounted on a high-speed handpiece under sterile water cooling. Pulp exposure was controlled, and the cavity was gently air-dried. Then 6 teeth were capped with Biodentine, 6 with TheraCal LC, and 6 with the experimental tricalcium silicate material. Biodentine and the experimental material were applied in bulk, and $2 \mathrm{~mm}$ was placed over the pulp. TheraCal LC was applied in 2 layers of $1 \mathrm{~mm}$ in depth, and each layer was light-cured for 20 seconds. During the setting time, the apical part of the teeth was dipped into sterile absorbent cotton soaked with the culture medium to avoid any desiccation during the preparation procedure. At the end of this period, the same diamond bur used for the cavity preparation was used to eliminate the residual cement on the enamel-dentin walls.

The teeth were restored by application of self-etching adhesive resin (Xeno III, Lot no. 1302001227; Dentsply DeTrey GmbH, Konstanz, Germany) and restoration with SDR (Dentsply DeTrey GmbH).

The roots were suspended into the minimum essential medium supplemented with $200 \mathrm{IU} / \mathrm{mL}$ penicillin, $200 \mu \mathrm{g} / \mathrm{mL}$ streptomycin, and $0.50 \mu \mathrm{g}$ amphotericin B (Fig. 1). The cultured teeth were incubated for 14 days, and media were changed every other day. At the end of the 14-day contact of the materials with the pulp, the teeth were removed from medium, vacuum desiccated, embedded in resin, and sectioned longitudinally under copious water irrigation through the mesial to distal axis, followed by polishing. The material hydration was assessed under the scanning electron microscope in back-scatter mode. A schematic drawing of the areas assessed for hydration is shown in Figure $1 E$.

\section{Assessment of Material Activity}

X-ray Diffraction Analysis. Phase analysis was carried out by using X-ray diffraction. Materials were allowed to set in HBSS for 14 

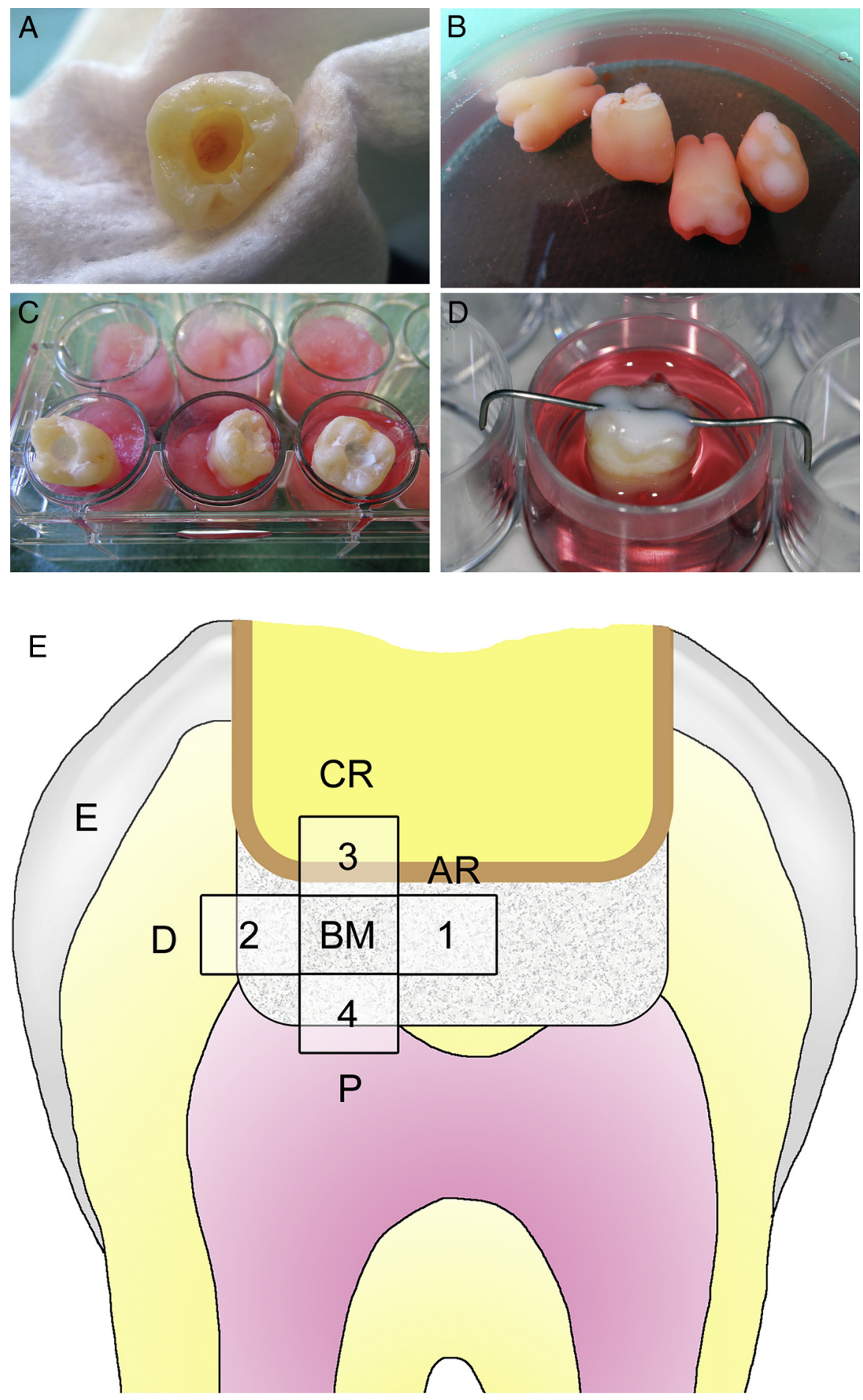

Figure 1. Pulp capping and entire tooth culture. Immature teeth were collected and cleaned, and pulp cavities were prepared $(A)$. Teeth with pulp cavities were placed in culture medium $(B)$. Pulp capping was performed, and teeth were placed onto sterile absorbent cotton soaked with culture medium for setting $(C)$. After bonding and placing the composite resin, teeth were then suspended in 12-well culture plates and cultured for 14 days $(D)$. $(E)$ Schematic representation of the capped tooth indicating the examined areas. Four representative areas indicated by numbers were examined: (1) within the biomaterial, (2) at the biomaterial/ dentin interface, (3) at the biomaterial/composite resin interface, and (4) at the biomaterial/pulp interface. AR, adhesive resin; BM, pulp-capping biomaterial; CR, composite resin; D, dentin; E, enamel; P, pulp.

days, after which they were dried in a vacuum desiccator and crushed to a very fine powder by using an agate mortar and pestle. The diffractometer (Rigaku, Tokyo, Japan) used $\mathrm{Cu} \mathrm{K} \alpha$ radiation at $40 \mathrm{~mA}$ and $45 \mathrm{kV}$, and the detector was set to rotate between $15^{\circ}$ and $45^{\circ}$, with a sampling width of $0.05^{\circ}$ and scan speed of $1 \%$ min at $15 \mathrm{rev} / \mathrm{min}$. Phase identification was accomplished by using a search-match software that uses International Centre for Diffraction Data database (Newtown Square, PA). 


\section{Assessment of Calcium Ion Release}

Six cylindrical specimens $(10 \mathrm{~mm}$ in diameter and $2 \mathrm{~mm}$ thick) were prepared. They were allowed to set for 24 hours at $37^{\circ} \pm 1^{\circ} \mathrm{C}$ and weighed, after which the materials were immersed in $5 \mathrm{~mL}$ HBSS at $37 \pm 1^{\circ} \mathrm{C}$ for 14 days. The cement pellets were removed from the storage solution and discarded. The storage solutions and a blank were assessed for calcium by using ion chromatography.

\section{Statistical Analysis}

The calcium ion release data were analyzed by using KruskalWallis nonparametric statistical test. $P<.05$ was considered significant.

\section{Results \\ Characterization of Set Materials Assessment of Hydration Stored in Aqueous Solution and after Pulp Capping. Material activity was assessed on pol-} ished sections of material allowed to set in $5 \mathrm{~mL}$ HBSS or alternatively in contact with dentin and pulp when used as a pulp-capping material. The indicator of material activity was the assessment of deposition of hydration product around the unhydrated cement particle and the material matrix. The extent of hydration of cement in contact with a free solution was compared with cement in contact with dentin and pulp.

The scanning electron micrographs of the hydrated materials in the different environments are shown in Figure 2. The prototype material TCS-Zr-20 in aqueous solution exhibited material hydration, with the cement particles being mostly hydrated and cement matrix saturated with reaction product. In the pulp-capped teeth, a similar degree of hydration was present in contact with the dentin (area 2) where the unhydrated cement particles were not evident, and material matrix was composed solely of hydration product. In the material core (area 1) the degree of hydration was less because the cement particles were evident, but some hydration had occurred because reaction rims were visible around the unhydrated cement particle. The material microstructure in contact with the composite resin (area 3) and in close proximity to the pulpal cavity (area 4) was different. There was some flocculation in contact with the pulp with areas devoid of radiopacifier. The material was mostly composed of reaction by-product in the $20 \mu \mathrm{m}$ located above the pulp chamber showing complete hydration of the cement in this area.

Biodentine exhibited more reaction by-product when compared with the prototype radiopacified tricalcium silicate-based material when stored in HBSS and also when used as a pulp cap. When used as a pulp cap, the material matrix (area 1) was completely filled with reaction by-product, and the unhydrated cement particles were absent. There was no difference in material microstructure in contact with dentin (area 2), composite (area 3), or over the pulp chamber (area 4). The microstructure of material used as a pulp cap was similar to that of the material stored in HBSS.

When stored in aqueous solution, Theracal LC exhibited some reaction by-product around the unhydrated cement particles but to a lesser extent than Biodentine and the prototype cement. The microstructure of Theracal LC after pulp capping was different from that of the material stored in contact with physiological solution. The reaction rims in the material in contact with the solution were more extensive, showing more material reaction in vitro. In the bulk of the material (area 2) there was little or no reaction by-product around the unhydrated cement particle. In contact with the dentin (area 3) the material was mostly composed of radiopacifier particles in a resin matrix. There were practically no cement particles visible. There was minimal material reaction in contact with the pulp chamber (area 4).

\section{Assessment of Material Activity}

X-ray Diffraction Analysis. The x-ray diffractograms of the test materials were overlayed to compare the phases present in the set material and are shown in Figure $3 \mathrm{~A}$. Calcium hydroxide peaks are evident at $18^{\circ} 2 \theta$ when using a copper tube. Biodentine exhibited a strong portlandite (calcium hydroxide) peak, followed by the prototype cement. Theracal LC did not show any peaks for calcium hydroxide. All the materials exhibited peaks for tricalcium silicate; Biodentine and TCS-Zr-20 exhibited peaks for zirconium oxide that were more intense for the latter. Theracal LC exhibited peaks for barium strontium zirconate.

\section{Assessment of Galcium Ion Release}

Biodentine exhibited the highest calcium ion release in solution when compared with the other materials. Theracal LC had the lowest calcium ion release. The nonparametric Kruskal-Wallis test revealed that the difference between all 3 materials was statistically significant $(P<.001)$.

\section{Discussion}

Material microstructure was assessed to evaluate whether tricalcium silicate-based materials hydrated when used in contact with the pulp-dentin complex, thus in an environment similar to their application conditions in vivo where availability of moisture is limited. For this purpose, an entire human tooth culture model that has been validated for the reproduction of pulp-capping conditions was used. Indeed, previous works have shown that this model reproduces the initial steps of dentin-pulp regeneration under pulp injuries and after pulp capping with biomaterials. In this model, pulp injuries to human teeth induced activation of pulp progenitor cells and their migration to the injury site (22). After direct capping with calcium hydroxide, MTA, or Biodentine, the progenitor cells differentiated into odontoblast-like cells and secreted a form of reparative dentin at the capping material application site $(5,23)$. These data clearly demonstrated the usefulness of this model to investigate the pulp-capping process as it reproduces the in vivo conditions.

The materials investigated in the current study included 2 commercially available tricalcium silicate-based pulp-capping agents and a prototype material composed of tricalcium silicate and zirconium oxide. The prototype material had a similar composition to Biodentine because it was composed of tricalcium silicate cement and zirconium oxide as a radiopacifier without including the additives found in Biodentine, namely calcium carbonate, calcium chloride, and water-soluble polymer, which are added to Biodentine to enhance its properties. The properties of the prototype material have already been investigated, and it was shown to hydrate forming calcium silicate hydrate and calcium hydroxide $(13,24)$ and exhibited a radiopacity higher than $3 \mathrm{~mm}$ aluminum thickness, low solubility, sorption, and fluid uptake, a compressive strength of $67 \mathrm{~N} / \mathrm{mm}^{2}$, and 48 Vickers hardness number microhardness value after 28 days of exposure to physiological solution (25).

The optimization of Biodentine was evident in the current study. Although Biodentine and TCS-Zr-20 were composed of similar materials, the former exhibited more advanced hydration both in vitro and after pulp capping. This was evident from the denser hydration product in the cement matrix and the absence of unhydrated cement particles after 14 days of hydration. The prototype material exhibited more advanced hydration in vitro when compared with the pulpcapping conditions. The leaching of calcium in Biodentine was higher, and calcium hydroxide was formed as a reaction by-product. This justifies the optimal biological effects of Biodentine on the pulp as demonstrated both in vitro and in vivo $(5,14-17)$. This would 

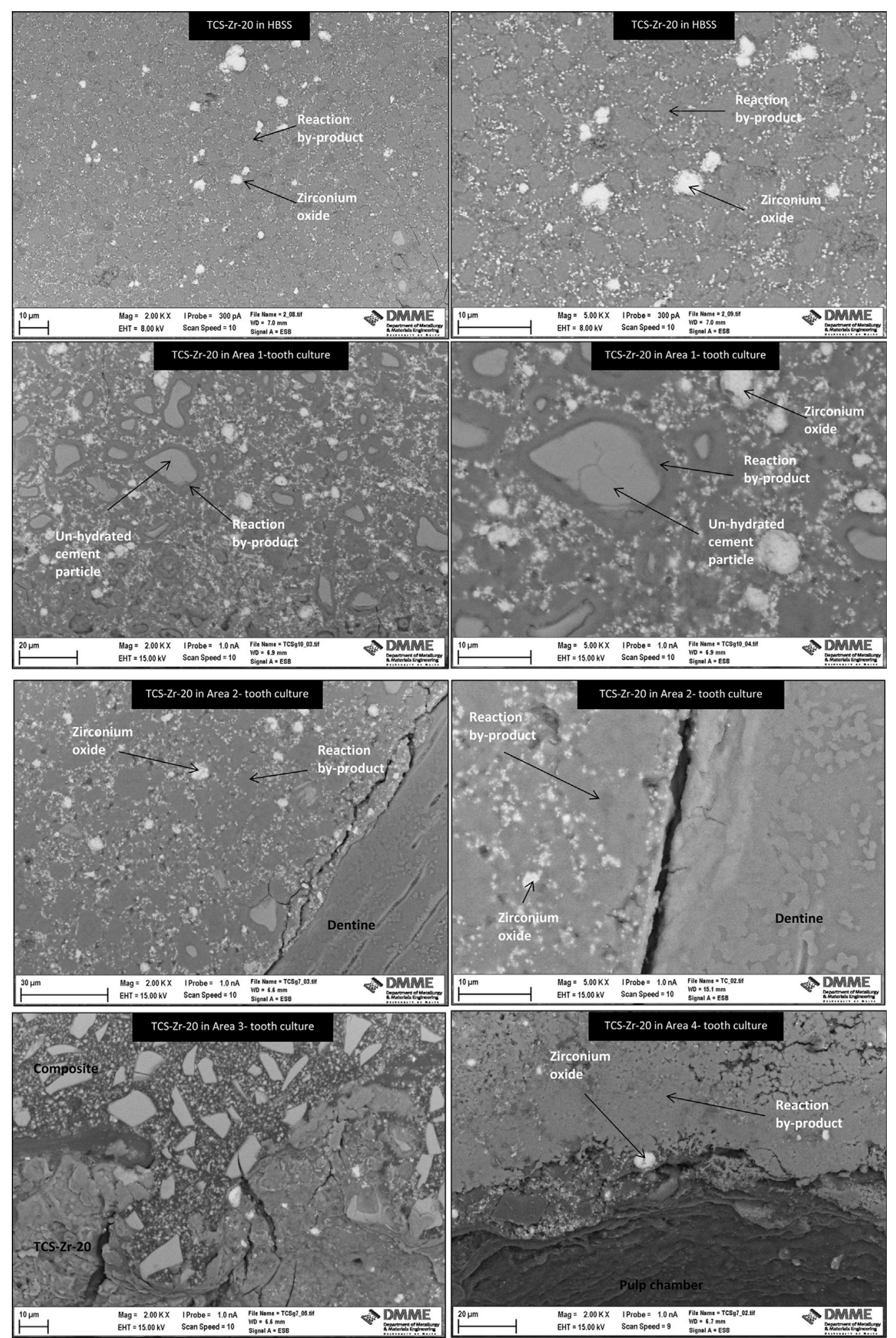

Figure 2. Back-scatter scanning electron micrographs of test materials after immersion in $\mathrm{HBSS}$ at $37^{\circ} \mathrm{C}$ or used as direct pulp-capping materials in tooth cultures for 14 days.

imply that the results obtained in this study for Theracal LC and the prototype material can be assumed to occur clinically.

Because Theracal LC is resin-modified, it does not use water as mixing fluid. The hydration of Theracal LC depends on fluid uptake through the resin matrix from the environment. The high calcium ion release of Theracal LC was demonstrated in vitro (18) where the material was stored in a solution where fluid uptake could occur unimpeded. Regardless of the high calcium ion leaching in vitro, Theracal 

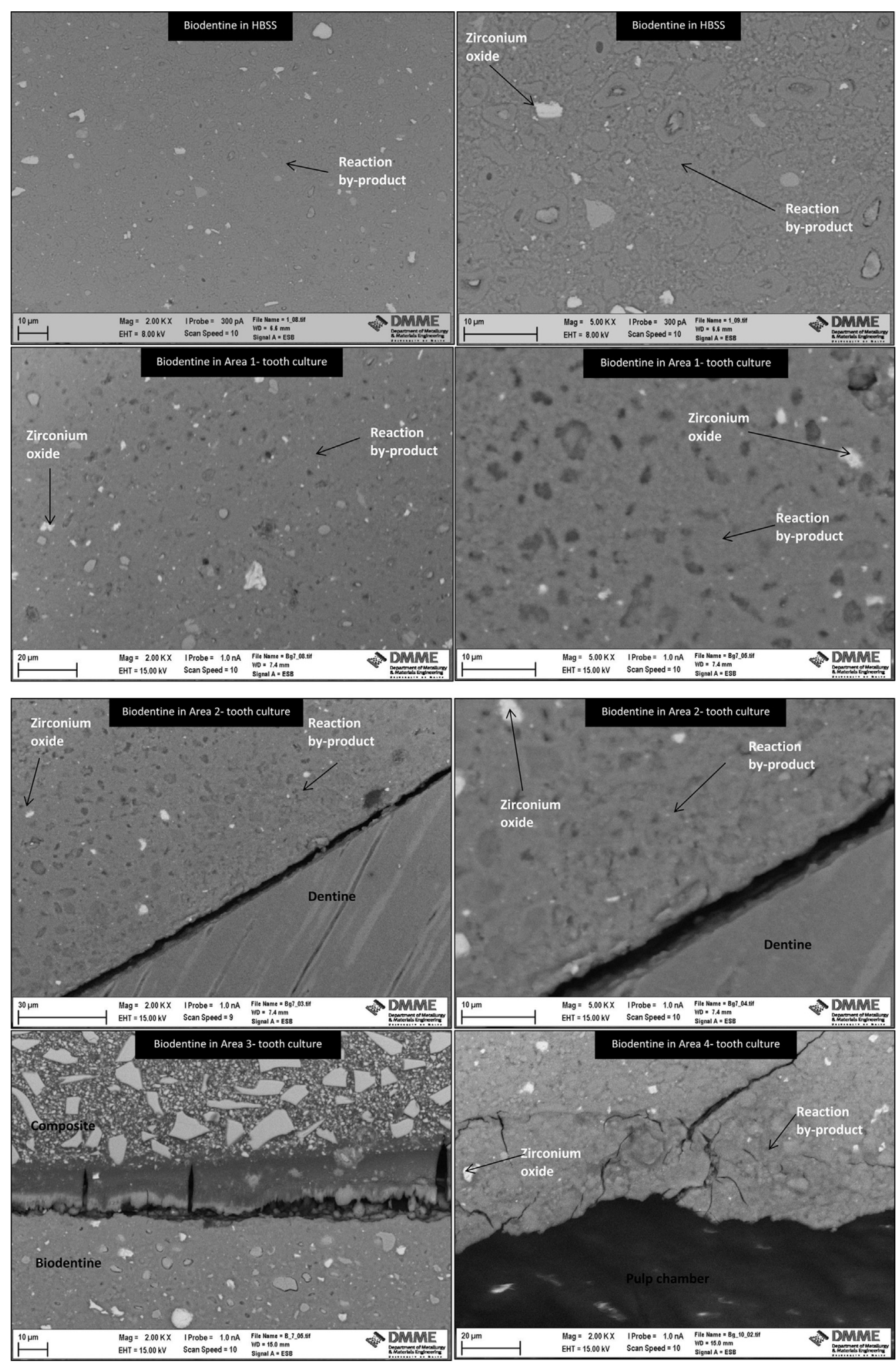

Figure 2. (continued).

LC was toxic to pulp cells (20). The findings in the current study could potentially explain the divergence shown in the previous research. In pulp-capping conditions, there is not enough moisture to allow proper hydration of the tricalcium silicate in Theracal LC. Even when in contact with several milliliters of solution, Theracal LC exhibited lower calcium ion leaching when compared with Biodentine. The calcium ions that leached from Theracal LC were not in hydroxide form because no calcium hydroxide was shown on x-ray diffraction analysis. This is in accordance with a recent study evaluating the hydration of Theracal LC (19) where no calcium hydroxide was formed after hydration, and the 

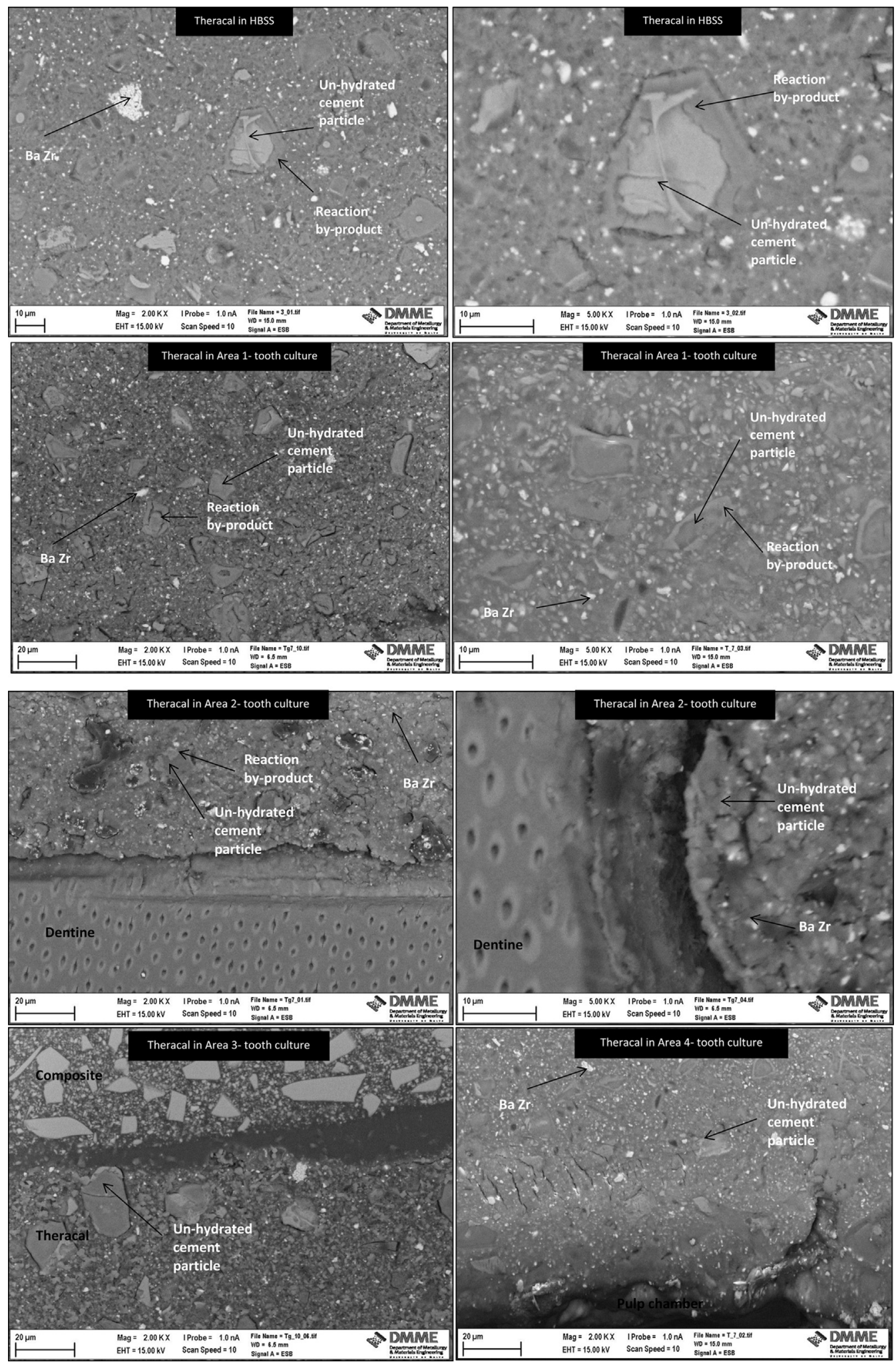

Figure 2. (continued).

calcium-releasing ability of Theracal LC was shown to be limited. For several years calcium hydroxide has been used as a pulp-capping material. The success of calcium hydroxide is mainly the result of stimulation of odontoblast activity and subsequent mineralization. The novel pulp-capping materials that are based on tricalcium silicate all allegedly release calcium hydroxide as a by-product of hydration. This has been demonstrated for MTA $(26)$ and also for Biodentine $(13,19)$. Although there is calcium ion release from hydrating Theracal LC, no calcium hydroxide is formed, as has been verified by x-ray diffraction analysis in the current study and in previous research (19). 
A
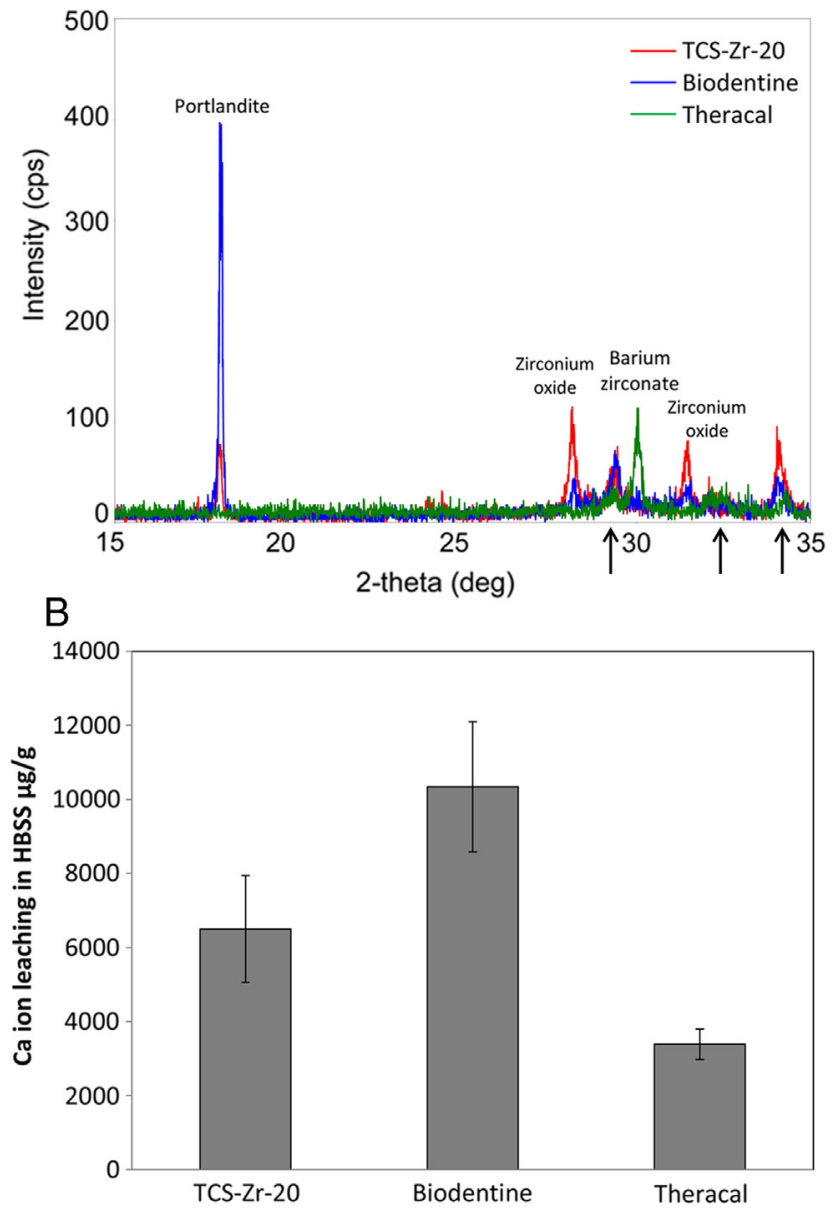

Figure 3. (A) X-ray diffraction analysis plots of test material showing portlandite (calcium hydroxide), tricalcium silicate (arrows), and radiopacifier peaks (zirconium oxide and barium zirconate) of varying intensities in the test materials. (B) Calcium ion leaching after 14-day immersion in HBSS for the test materials. The difference was statistically significant among the 3 materials $(P<.001)$.

Dental resins depend on micromechanical bonding for optimal adhesion to dental hard structures. Bonding of Theracal LC to dentin thus would require acid etching of the dentin. Application of acid in close proximity to the dental pulp would result in adverse pulpal reactions. A total-etch or self-etch adhesive has been recommended recently for use with Biodentine because of its claimed inherent weakness in its early setting phase (27). In the current study, a self-etch adhesive was placed over the materials, and a composite resin was used to restore the teeth. This allowed the reproduction of the clinical application conditions of these materials in our tooth culture model.

\section{Conclusions}

Theracal LC hydration after pulp capping is incomplete because of the limitation of moisture diffusion from the pulp-dentin complex into the material. Biodentine composition is optimized, and the environmental conditions did not affect material microstructure or hydration. Biodentine exhibited formation of calcium hydroxide and calcium ion leaching, which are beneficial to the dental pulp.

\section{Acknowledgments}

The authors thank Dr Jean-Charles Gardon for the teeth extraction, Dr Francois Sorrentino of Mineral Research Processing, Bisco, and Septodont for the materials, and IngJames Camilleri of the Department of Metallurgy and Materials Engineering, Faculty of Engineering, University of Malta and Mr Lawrence Spiteri of Diagnostic Science Laboratories for their technical expertise.

The authors thank ERDF (Malta) for the financing of the testing equipment through the project "Developing an Interdisciplinary Material Testing and Rapid Prototyping RED Facility" (Ref. no. 012). Aix-Marseille University and the National center of scientific research provided institutional financial support.

The authors deny any conflicts of interest related to this study.

\section{References}

1. Torabinejad M, Chivian N. Clinical applications of mineral trioxide aggregate. J Endod 1999;25:197-205.

2. Camilleri J, Montesin FE, Brady K, et al. The constitution of mineral trioxide aggregate. Dent Mater 2005;21:297-303.

3. Graham L, Cooper PR, Cassidy N, et al. The effect of calcium hydroxide on solubilisation of bio-active dentine matrix components. Biomaterials 2006;27:2865-73.

4. Tomson PL, Grover LM, Lumley PJ, et al. Dissolution of bio-active dentine matrix components by mineral trioxide aggregate. J Dent 2007;35:636-42.

5. Laurent P, Camps J, About I. Biodentine(TM) induces TGF- $\beta 1$ release from human pulp cells and early dental pulp mineralization. Int Endod J 2012;45:439-48.

6. Leye Benoist F, Gaye Ndiaye F, Kane AW, et al. Evaluation of mineral trioxide aggre-

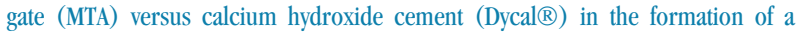
dentine bridge: a randomised controlled trial. Int Dent J 2012;62:33-9.

7. Petrou MA, Alhamoui FA, Welk A, et al. A randomized clinical trial on the use of medical Portland cement, MTA and calcium hydroxide in indirect pulp treatment. Clin Oral Investig 2014;18:1383-9.

8. Hilton TJ, Ferracane JL, Mancl L. Comparison of CaOH with MTA for direct pulp capping: a PBRN randomized clinical trial. J Dent Res 2013;92(Suppl):S16-22.

9. Eskandarizadeh A, Shahpasandzadeh MH, Shahpasandzadeh M, et al. A comparative study on dental pulp response to calcium hydroxide, white and grey mineral trioxide aggregate as pulp capping agents. J Conserv Dent 2011;14:351-5.

10. Camilleri J. Scanning electron microscopic evaluation of the material interface of adjacent layers of dental materials. Dent Mater 2011;27:870-8.

11. Eid AA, Komabayashi T, Watanabe E, et al. Characterization of the mineral trioxide aggregate-resin modified glass ionomer cement interface in different setting conditions. J Endod 2012;38:1126-9.

12. Goldberg M, Pradelle-Plasse N, Tran XV, et al. Emerging trends in (bio)material research. In: Goldberg M, ed. Biocompatibility or Cytotoxic Effects of Dental Composites, 1st ed. Oxford, UK: Coxmoor Publishing Company; 2009:181-203.

13. Camilleri J, Sorrentino F, Damidot D. Investigation of the hydration and bioactivity of radiopacified tricalcium silicate cement, Biodentine and MTA Angelus. Dent Mater 2013;29:580-93.

14. Zanini M, Sautier JM, Berdal A, et al. Biodentine induces immortalized murine pulp cell differentiation into odontoblast-like cells and stimulates biomineralization. J Endod 2012;38:1220-6.

15. Shayegan A, Jurysta C, Atash R, et al. Biodentine used as a pulp-capping agent in primary pig teeth. Pediatr Dent 2012;34:e202-8.

16. Tran XV, Gorin C, Willig C, et al. Effect of a calcium-silicate-based restorative cement on pulp repair. J Dent Res 2012;91:1166-71.

17. Nowicka A, Lipski M, Parafiniuk M, et al. Response of human dental pulp capped with biodentine and mineral trioxide aggregate. J Endod 2013;39:743-7.

18. Gandolfi MG, Siboni F, Prati C. Chemical-physical properties of TheraCal, a novel light-curable MTA-like material for pulp capping. Int Endod J 2012; 45:571-9.

19. Camilleri J. Hydration characteristics of Biodentine and Theracal used as pulp capping materials. Dent Mater 2014;30:709-15.

20. Hebling J, Lessa FC, Nogueira I, et al. Cytotoxicity of resin-based light-cured liners. Am J Dent 2009;22:137-42.

21. Han L, Okiji T. Bioactivity evaluation of three calcium silicate-based endodontic materials. Int Endod J 2013;46:808-14.

22. Téclès $O$, Laurent $P$, Zygouritsas $S$, et al. Activation of human dental pulp progenitor/ stem cells in response to odontoblast injury. Arch Oral Biol 2005;50:103-8.

23. Téclès 0 , Laurent $P$, Aubut $V$, About I. Human tooth culture: a study model for reparative dentinogenesis and direct pulp capping materials biocompatibility. J Biomed Mater Res B Appl Biomater 2008;85:180-7. 
Basic Research-Technology

24. Grech L, Mallia B, Camilleri J. Characterization of set Intermediate Restorative Material, Biodentine, Bioaggregate and a prototype calcium silicate cement for use as root-end filling materials. Int Endod J 2013;46:632-41.

25. Grech L, Mallia B, Camilleri J. Investigation of the physical properties of tricalcium silicate cement-based root-end filling materials. Dent Mater 2013;29:e20-8.
26. Camilleri J. Characterization of hydration products of mineral trioxide aggregate. Int Endod J 2008;41:408-17.

27. Hashem DF, Foxton R, Manoharan A, et al. The physical characteristics of resin composite-calcium silicate interface as part of a layered/laminate adhesive restoration. Dent Mater 2014;30:343-9. 